\title{
QUALIDADE DE MAMÃO 'GOLDEN’ MINIMAMENTE PROCESSADO ARMAZENADO EM DIFERENTES TEMPERATURAS
}

\section{QUALITY OF FRESH-CUT PAPAYA 'GOLDEN' STORED AT DIFFERENT TEMPERATURES}

\author{
Luiz Fernando Ganassali OLIVEIRA JR \\ Lanamar Almeida CARLOS ${ }^{2}$ \\ Carlos Alberto Martins CORDEIRO 3 \\ Enilce Maria COELHO ${ }^{4}$ \\ Thiago Rezende ARAÚJO 5
}

\begin{abstract}
RESUMO
Neste trabalho, foi estudado o efeito da temperatura de armazenagem na conservação de mamão minimamente processado. Os mamões, previamente resfriados à temperatura de $6 \stackrel{\circ}{\circ}$, foram submetidos à seleção, lavagem, sanitização, corte em cubos, enxágüe, e acondicionamento em embalagens plásticas de polietileno de baixa densidade rígido e armazenados em câmaras frias nas temperaturas de 5 e $10^{\circ} \mathrm{C}$ por 8 dias. Avaliou-se $\mathrm{pH}$, acidez titulável, sólidos solúveis totais, vitamina $\mathrm{C}$ e contaminações microbiológicas no mamão minimamente processado. O delineamento experimental utilizado foi o inteiramente casualizado, com três repetições. A acidez titulável foi menor com a maior temperatura. As análise de vitamina $\mathrm{C}$ e pH não apresentaram diferença significativa entre as temperaturas de armazenamento. Os teores de sólidos solúveis não variaram entre os tratamentos, e os cuidados higiênicos adotados durante o processamento permitiram a obtenção de produtos com baixa contagem microbiana, no produto armazenado a $5^{\circ} \mathrm{C}$ após 8 dias. Estes resultados permitem indicar o mamão para a produção de produtos minimamente processados, na forma de pedaços, com conservação a $5^{\circ} \mathrm{C}$ por um período de 8 dias.
\end{abstract}

Palavras-chave: Carica papaya L.; vida de prateleira; microbiologia.

\begin{abstract}
This research studied the effect of storage temperature on the preservation of fresh-cut papaya. The papaya, previously cooled to a temperature of $6^{\circ} \mathrm{C}$, were selected, washed, sanitized, cuted in cubs, rinsed, and stored in plastic packaging of low density polyethylene rigid, and then stored at 5 and $10^{\circ} \mathrm{C}$ for 8 days. The following aspects were evaluated: $\mathrm{pH}$, titratable acidity, soluble solids, vitamin $\mathrm{C}$ and microbiological in the fresh-cut papaya. The experimental design was completely randomized, with three repetitions. The titratable acidity was lower with the highest temperature. The analysis for the vitamin $\mathrm{C}$ and $\mathrm{pH}$, did not presented significant variation between the temperatures and days of storage The total soluble solids content did not vary between treatments, and hygienic care adopted during processing allowed to obtain low microbial counting products, in chunks stored at $5^{\circ} \mathrm{C}$ after 8 days. These results allow to indicate papaya for fresh-cuts production, in chunk form, with refrigerated conservation $\left(5^{\circ} \mathrm{C}\right)$ for 8 day periods.
\end{abstract}

Key-words: Carica papaya L.; shelf life; microbiology.

'Eng. Agrônomo, D.S. em Fisiologia Vegetal, UFES/Botânica. E-mail: Ifg@pq.cnpq.br ${ }^{2}$ Química, M.S. em Tecnologia de Alimentos, UENF/CCTA

${ }^{3}$ Químico, D.S. em Tecnologia de Alimentos, FACUTEC

${ }^{4}$ Eng. Alimentos, D.S. Eng. Agrícola, CEFET/Campos

${ }^{5}$ Químico, M.S em Química, UENF/CCT 


\section{INTRODUÇÃO}

Dentre as mais importantes frutas tropicais atualmente cultivadas no mundo, o mamão ocupa, evidentemente, um lugar de destaque (MEDINA, 1995). Segundo a FAO (2000), o Brasil é o país que mais produz mamão em escala internacional, concentrando $31,6 \%$ da oferta mundial, seguido da Nigéria com 13,9\%, México com 10,7\% e Indonésia com $9,1 \%$. Os frutos frescos são parte essencial de uma dieta humana balanceada. São ricos em vitamina $C$, carotenóides [provitamina $A$ ], sais minerais e carboidratos e, apreciados por suas excelentes propriedades sensoriais, em particular por sua cor, aroma e sabor (THOMAS, 1986).

Nos dias atuais, onde o tempo é cada vez mais escasso e os consumidores mais exigentes, torna-se necessário mais praticidade e rapidez nos preparos dos pratos. Assim, nos últimos anos, temse percebido mudanças significativas nos hábitos alimentares da população brasileira (SOUZA, 2001). Os produtos minimamente processados fazem parte de um segmento da indústria hortifrutícula que vem obtendo crescente participação no mercado de produtos frescos, em virtude da procura de qualidade de vida que faz com que as pessoas procurem alimentos mais saudáveis. No Brasil, a utilização desses produtos teve início no princípio da década de 1990 e seu consumo vem aumentando consideravelmente. Isso porque as hortaliças e frutos minimamente processados oferecem inúmeros benefícios ao consumidor, por serem extremamente práticos, mantendo, ainda, suas características sensoriais, nutricionais e microbiológicas (CATWELL, 1998; CATWELL e SUSLOW, 2002).

O consumo de hortaliças e frutas préprocessados representa, em média, 2,9\% do total de produtos hortifrutícolas, entretanto, pesquisas realizadas com supermercados apontam nítida tendência no crescimento da demanda por estes produtos, pois $66 \%$ dos estabelecimentos planejam aumentar a oferta de produtos convenientes. Alguns dos problemas que têm limitado a expansão na comercialização de hortifrutis pré-processados, dentre outros, são os preços altos, a pouca variedade de produtos e as pequenas quantidades que causam interrupções no fluxo de fornecimento (ANONIMO, 2002).

O processamento mínimo inclui operações de seleção, lavagem, descascamento e corte, visando obter um produto fresco e conveniente para o preparo e consumo (BURNS, 1995). A durabilidade deste tipo de produto é extremamente baixa se comparada ao produto inteiro, considerando que nas superfícies do corte, as células e a membrana celular são destruídas e ocorre alteração no metabolismo celular. Esta alteração no metabolismo, que inclui aumento na respiração e produção de etileno, resulta em redução drástica na vida pós-colheita do produto préprocessado (CHITARRA, 1998).

Entretanto, as frutas minimamente processadas ainda são um desafio, devido à falta de conhecimento a respeito do comportamento fisiológico, químico e bioquímico. As operações envolvidas na preparação de frutas minimamente processadas, geralmente, são responsáveis pela curta vida útil das mesmas, a qual fica restrita, em alguns casos, a somente 3-4 dias (O'CONNORSHAW et al., 1994).

O objetivo deste trabalho foi avaliar os aspectos qualitativos e microbiológicos de mamões, quando submetidos ao processamento mínimo e armazenados sob diferentes temperaturas.

\section{MATERIAL E MÉTODOS}

Foram utilizados mamões (Carica papaya L.) da cultivar 'Golden', selecionados por tamanho; livres de ferimentos ocasionados por patógenos ou pelo transporte; e a casca apresentando coloração amarela. Os mamões foram lavados, resfriados a 6 ${ }^{\circ} \mathrm{C}$ e sanitizados com hipoclorito de sódio na concentração de 200 ppm durante 5 minutos, descascados e em seguida, foram cortados em cubos de aproximadamente $2 \mathrm{~cm}$ de aresta. Após 0 processo, os pedaços foram enxaguados com a solução de hipoclorito de sódio a 20 ppm e colocadas sobre papel absorvente para remoção da solução em excesso. Em seguida, os mamões foram acondicionados nas embalagens rígidas de polietileno de baixa densidade de $70 \mu \mathrm{m}$ (PEBD-70), com tampas acopladas e capacidade para $350 \mathrm{~mL}$, e armazenados em estufas do tipo B.O.D., sob diferentes temperaturas $\left(5\right.$ e $\left.10^{\circ} \mathrm{C}\right)$ e umidade relativa de $95 \%$ durante 8 dias.

O delineamento experimental foi inteiramente ao acaso em esquema fatorial $2 \times 5$ ( 2 temperaturas e 5 períodos de avaliação). Utilizaramse 3 repetições com aproximadamente $200 \mathrm{~g}$ de mamão minimamente processado.

A cada dois dias foram retiradas amostras dos dois tratamentos, a $5^{\circ} \mathrm{C} \mathrm{e} 10^{\circ} \mathrm{C}$ para as seguintes análises: a) teor de sólidos solúveis (TSS), obtido por meio de homogeneização da polpa, de onde uma gota foi retirada e colocada na lente do refratômetro digital ATAGO, modelo PR 201, e o valor obtido expresso em ${ }^{\circ} \mathrm{BRIX}$; b) acidez titulável (AT), obtida pela titulação de uma alíquota de suco com solução $0,1 \mathrm{~mol} \mathrm{~L}^{-1}$ de $\mathrm{NaOH}$, em presença de fenolftaleína, para um $\mathrm{pH}$ de 8,0 , e o valor obtido expresso em $\mathrm{mg}$ de ácido cítrico $100 \mathrm{~mL}^{-1}$ de suco (AOAC, 1992); c) $\mathrm{pH}$, por potenciometria (AOAC, 1992); d) vitamina C (VC), obtida por meio de cromatografia líquida de alta eficiência (HPLC), e o valor obtido expresso em $\mathrm{mg} 100 \mathrm{~g}^{-1}$ de ácido ascorbico (GADNER et al., 2000).

As amostras também foram analisadas quanto ao desenvolvimento de bolores e leveduras, coliformes totais, enterobacterias e salmonella (VANDERZANT e SPLITTSTOESSER, 1992). Foram retiradas $25 \mathrm{~g}$ de amostra e previamente homogeneizadas em $225 \mathrm{~mL}$ de água peptonada (diluição $10^{-2}$ ) sob agitação por 15 minutos. A seguir foi transferido assepticamente $1 \mathrm{~mL}$ de cada amostra para os respectivos tubos de ensaio contendo $9 \mathrm{~mL}$ de água peptonada esterilizada (diluição $10^{-2}$ ). A partir dessa diluição procedeu-se à diluição decimal seriada, utilizando-se água peptonada como diluente, sendo tais diluições usadas para análises 
subseqüentes. Para a determinação desses microrganismos foi empregada a técnica de contagem em placas de Petri, utilizando-se semeadura por profundidade em ágar dextrose acidificado com ácido tartárico a $10 \%(\mathrm{pH}=4,0)$, com incubação a $25^{\circ} \mathrm{C}$ durante 5 dias. Os resultados foram expressos em unidades formadoras de colônias $\mathrm{g}^{-1}$ de amostra.

Para a determinação de E. coli, Coliformes totais, Enterobactérias e Salmonella trasnferiram-se alíquotas apropriadas das diluições das amostras de mamão minimamente processada para placas de Petri, em duplicata, contendo ágar Chromocult. A incubação foi a $35{ }^{\circ} \mathrm{C}$ durante 48 h. A identificação de cada microrganismos deu-se pela coloração diferencial E. coli (coloração marrom com alo claro), Coliformes totais (coloração roxa), Enterobactérias (coloração creme), e Salmonella (coloração verde).
OLIVEIRA JR, L. F. G. et al. Qualidade de mamão...

Os resultados foram expressos em unidades formadoras de colônias/g de amostra.

Os resultados das análises fisico-químicas foram submetidos à análise do desvio padrão, onde a diferença entre dois tratamentos maior que a soma de dois desvios padrões foram consideradas significativas a $5 \%$ de probabilidade (MORETTI et al, 2002). Para a análise microbiológica os resultados foram submetidos à análise de variância, e teste t a $5 \%$ de probabilidade.

\section{RESULTADOS E DISCUSSÃO}

Durante todo período de armazenamento não foi detectado a presença de enterobactérias nas duas temperaturas de armazenamento, sendo que os valores foram inferiores a $10^{2} \mathrm{UFC} \mathrm{g}^{-1}$ (Tabela 1).

TABELA 1. Análise microbiológica de mamões 'Golden' minimamente processados e armazenados em duas temperaturas.

\begin{tabular}{lllllll}
\hline $\begin{array}{l}\text { Temp. } \\
\left({ }^{0} \mathrm{C}\right)\end{array}$ & $\begin{array}{l}\text { Tempo } \\
\text { (dias) }\end{array}$ & $\begin{array}{l}\text { E. coli } \\
(\mathrm{UFC} / \mathrm{g})\end{array}$ & $\begin{array}{l}\text { Salmonella sp. } \\
\text { (presença }(+))\end{array}$ & $\begin{array}{l}\text { Coliformes } \\
\text { totais } \\
\text { (UFC/g) }\end{array}$ & $\begin{array}{l}\text { Enterobactérias } \\
(\text { UFC/g) }\end{array}$ & $\begin{array}{l}\text { Bolores e } \\
\text { leveduras } \\
(\text { UFC/g) }\end{array}$ \\
\hline 5 & 0 & $<10^{2} \mathrm{a}$ & {$[-]$} & $<10^{2} \mathrm{a}$ & $<10^{2} \mathrm{a}$ & $<10^{2} \mathrm{a}$ \\
& 2 & $<10^{2} \mathrm{a}$ & {$[-]$} & $<10^{2} \mathrm{a}$ & $<10^{2} \mathrm{a}$ & $<10^{2} \mathrm{a}$ \\
& $<$ & $<10^{2} \mathrm{a}$ & {$[-]$} & $<10^{2} \mathrm{a}$ & $<10^{2} \mathrm{a}$ & $<10^{2} \mathrm{a}$ \\
& $<$ & $<10^{2} \mathrm{a}$ & {$[-]$} & $<10^{2} \mathrm{a}$ & $<10^{2} \mathrm{a}$ & $<10^{2} \mathrm{a}$ \\
& $<$ & $<10^{2} \mathrm{a}$ & {$[-]$} & $<10^{2} \mathrm{a}$ & $<10^{2} \mathrm{a}$ & $<10^{2} \mathrm{a}$ \\
\hline 10 & $<$ & $<10^{2} \mathrm{a}$ & {$[-]$} & $<10^{2} \mathrm{a}$ & $<10^{2} \mathrm{a}$ & $<10^{2} \mathrm{a}$ \\
& $<$ & $<10^{2} \mathrm{a}$ & {$[-]$} & $4,2 \times 10^{2} \mathrm{~b}$ & $<10^{2} \mathrm{a}$ & $<10^{2} \mathrm{a}$ \\
& $<$ & $<10^{2} \mathrm{a}$ & {$[-]$} & $5,4 \times 10^{3} \mathrm{c}$ & $<10^{2} \mathrm{a}$ & $<10^{2} \mathrm{a}$ \\
& $<$ & $510^{2} \mathrm{a}$ & {$[-]$} & $5,3 \times 10^{3} \mathrm{c}$ & $<10^{2} \mathrm{a}$ & $5,4 \times 10^{4} \mathrm{~b}$ \\
\hline
\end{tabular}

${ }^{*}$ As médias seguidas por pelo menos uma mesma letra, minúscula nas colunas não diferem entre si, a $5 \%$ de probabilidade, pelo teste $t$

[-] ausência

A presença de coliformes totais não foi detectada nos mamões armazenados a $5^{\circ} \mathrm{C},\left(<10^{2}\right.$ UFC $\left.\mathrm{g}^{-1}\right)$. Estes resultados mostram a eficiência dos cuidados higiênicos e ação positiva do hipoclorito de sódio na desinfecção conforme observado por HONG e GROSS (1998), assim como o efeito da temperatura de $5^{\circ} \mathrm{C}$. Para 0 tratamento $10^{\circ} \mathrm{C}$ verificou-se o surgimento de coliformes a partir do $4^{\circ}$ dia de armazenamento alcançando valores em torno de 5,4 $10^{3}$ UFC g ${ }^{-1}$ de produto. Podendo-se assim inferir que o aumento da deterioração e do crescimento microbiana está relacionado com o aumento da temperatura, também constatado por O'CONNOR-SHAW et al. (1994).

Os resultados obtidos nas determinações de Salmonella e E. coli nas amostras de mamão minimamente processados durante o período de armazenamento nas duas temperaturas encontraram-se de acordo com os padrões microbiológicos estabelecidos pela resolução ANVISA (2001) da Agência Nacional da Vigilância Sanitária, apresentando ausência de Salmonella e E. coli em $25 \mathrm{~g}$ de amostra, indicando boas praticas de sanitização e higiene durante a fabricação do produto.

Quanto a bolores e leveduras, verificou-se valores superiores a $5,1 \times 10^{4} \mathrm{UFC} \mathrm{g}^{-1}$ apenas durante o armazenamento a $10^{\circ} \mathrm{C}$ e após o sexto dia de conservação. A inibição do desenvolvimento de bolores e leveduras foi devido à baixa temperatura $\left(5^{\circ} \mathrm{C}\right)$ de armazenamento e provavelmente também em função da atmosfera modificada promovida pela embalagem que resultou em baixos níveis de $\mathrm{O}_{2}$ e altos de $\mathrm{CO}_{2}$ (ZAGORY e KADER, 1988; LEE et al., 1991; OLIVEIRA-JR et al., 2004). MOHD-SOM et al. (1994) verificaram, em brócolis minimamente processados, o não surgimento de bolores e leveduras, creditando o fato a micro atmosfera formada pela embalagem e a própria respiração do produto além da refrigeração.

Embora não existam, na legislação brasileira vigente, legislação especifica para mamões minimamente processados, em termos de padrões 
microbiológicos, tem sido preconizado que alimentos contendo contagens microbianas acima de $10^{5}$ e $10^{6}$ UFC g ${ }^{-1}$ podem ser impróprios para o consumo humano por causa da perda do valor nutricional, alterações organolépticas e riscos de contaminação (VITTI et al., 2004). Desta forma verificou-se neste trabalho a estreita relação da temperatura com o desenvolvimento de microrganismos.

Não foi verificada diferença significativa nos valores médios de $\mathrm{pH}$ entre os tratamentos estudados (Figura 1). Os valores se encontraram numa faixa de 5,65 a 5,30 , os quais enquadram-se na faixa entre 5,0 e 6,0 , verificada em mamões Golden acondicionados em atmosfera modificada (OLIVEIRA $\mathrm{JR}, 2002)$. Tanto o armazenamento a $5^{\circ} \mathrm{C}$ quanto a $10^{\circ} \mathrm{C}$ apresentaram praticamente a mesma tendência para os valores de $\mathrm{pH}$, não verificando influência da temperatura. As pequenas variações apresentadas são provavelmente decorrentes da variabilidade da matéria prima, verificada também por PEREIRA et al. (2003) ao trabalhar com goiabas minimamente processadas.

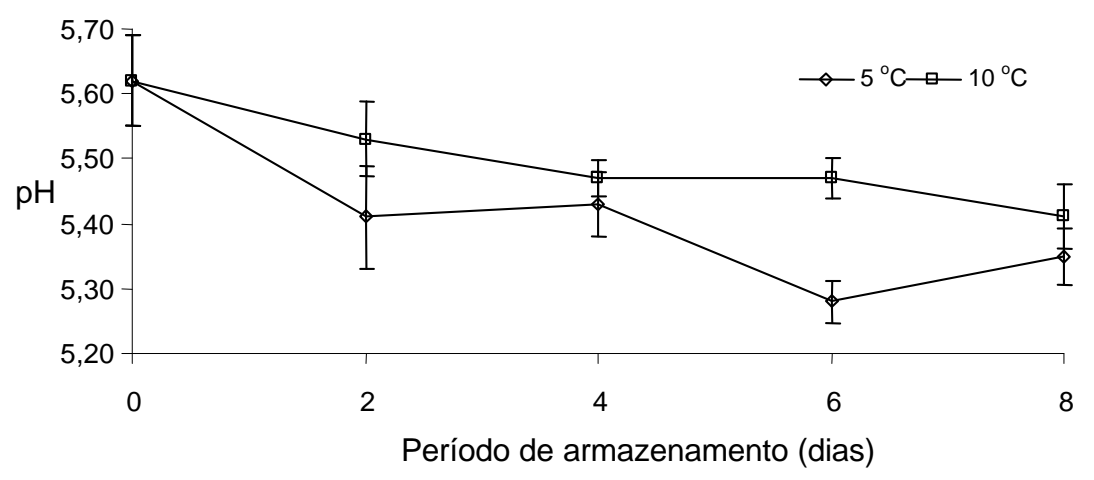

FIGURA 1 - pH da polpa de mamão minimamente processado armazenados a $5{ }^{\circ} \mathrm{C}$ e a $10{ }^{\circ} \mathrm{C}$ durante o período de 8 dias. Barras verticais representam o desvio padrão da média $(n=3)$.

A acidez titulável apresentou a mesma tendência, tanto para os mamões armazenados a temperatura de $5{ }^{\circ} \mathrm{C}$ quanto os armazenadas a $10^{\circ} \mathrm{C}$ (Figura 2). Verificou-se também maior acidez no $6^{\circ}$ e $8^{\circ}$ dia para os mamões armazenados a $5{ }^{\circ} \mathrm{C}$. A maior acidez em temperatura mais baixa, possivelmente foi devido ao metabolismo menos intenso dos mesmos em função da baixa temperatura (TEIXEIRA et al., 2001).

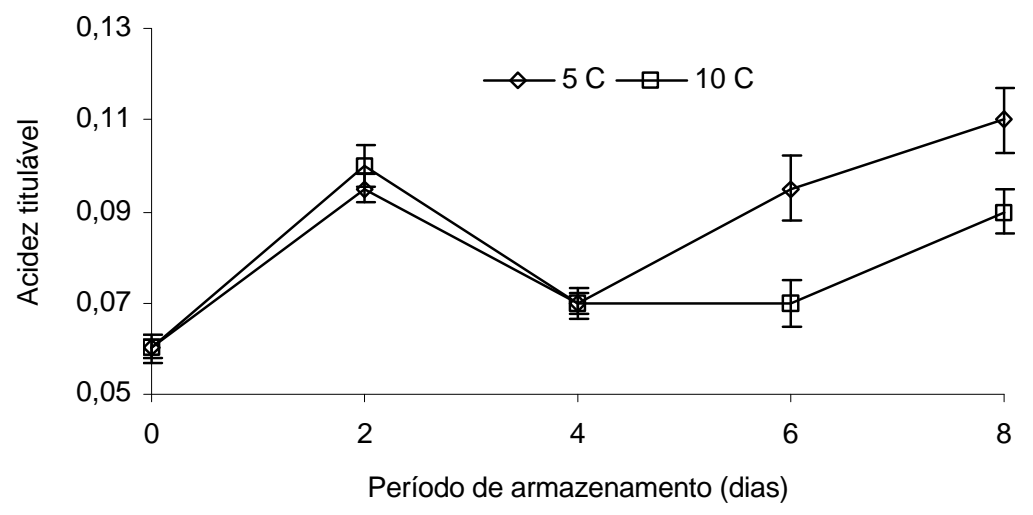

FIGURA 2 - Acidez titulável (mg ácido cítrico/100 ml de suco) da polpa de mamão minimamente processado armazenados a $5^{\circ} \mathrm{C}$ e a $10^{\circ} \mathrm{C}$ durante o período de 8 dias. Barras verticais representam 0 desvio padrão da média $(\mathrm{n}=3)$.

A diminuição da acidez ocorrida no $4^{\circ}$ dia pode ser justificada pelo consumo do próprio fruto, na tentativa de se manter funcional, pois os ácidos orgânicos são encontrados nos vacúolos das células na forma livre e combinados com sais, ésteres e glicosídeos, como fonte importante de energia para os vegetais, durante o processo de maturação, sendo que, durante 0 amadurecimento e no armazenamento, os mesmos sofrem oxidação no ciclo de Krebs (KLUGE et al., 2002).

Quanto aos teores de sólidos solúveis, não se observou efeito significativo dos tratamentos ao longo do período de armazenamento, observado também por TEIXEIRA et al. (2001) durante o armazenamento de mamão 'Formosa' minimamente processado. Verificou-se que a tendência 
apresentada pelas duas temperaturas de armazenamento foram praticamente as mesmas (Figura 3), diferindo-se apenas entre os tratamentos no $6^{\circ}$ dia com maior valor para os mamões armazenados a $10^{\circ} \mathrm{C}$, com $13,4^{\circ}$ Brix, e $10,5^{\circ}$ Brix,
OLIVEIRA JR, L. F. G. et al. Qualidade de mamão...

para mamões armazenadas a $10{ }^{\circ} \mathrm{C}$ e $5 \stackrel{\circ}{\circ}$, respectivamente. Tal variação apresentada pode ter sido provavelmente em função da variabilidade da matéria-prima.

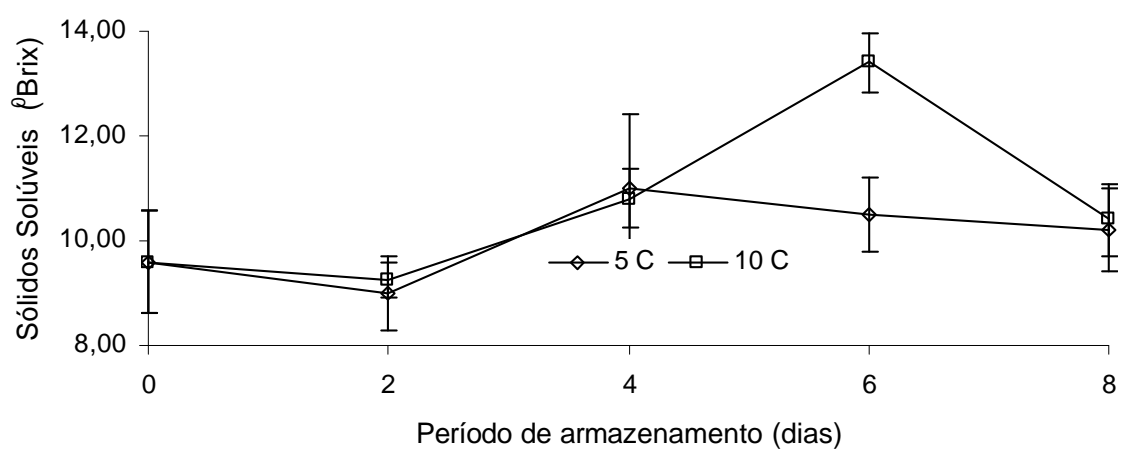

FIGURA 3 - Teor de sólidos solúveis totais da polpa de mamão minimamente processado armazenados a $5{ }^{\circ} \mathrm{C}$ e a $10^{\circ} \mathrm{C}$ durante o período de 8 dias. Barras verticais representam o desvio padrão da média $(n=3)$.

Quanto aos teores de vitamina C ocorreu um ligeiro declínio até o $4^{\circ}$ dia para a temperatura de $5^{\circ} \mathrm{C}$, e até o $2^{\circ}$ dia para a temperatura de $10^{\circ} \mathrm{C}$, seguido por incremento até o 6 dia para ambas as temperaturas (Figura 4). O teor de ácido ascórbico pode ser menor nos produtos vegetais minimamente processados quando comparado ao dos produtos intactos (KLEIN, 1987). Isso porque se considera que os danos decorrentes do corte podem conduzir à perda desse ácido, uma vez que é suscetível à degradação quando em presença de luz e oxigênio. O ácido ascórbico pode ser oxidado por meio da ação de enzimas, como ascorbato oxidase, polifenol oxidase, citocromo oxidase e peroxidase (KLEIN, 1987). Desta forma pode-se inferir que a perda de vitamina $\mathrm{C}$ em mamões minimamente processado pode variar de acordo com a espécie e condições de armazenamento principalmente temperatura.

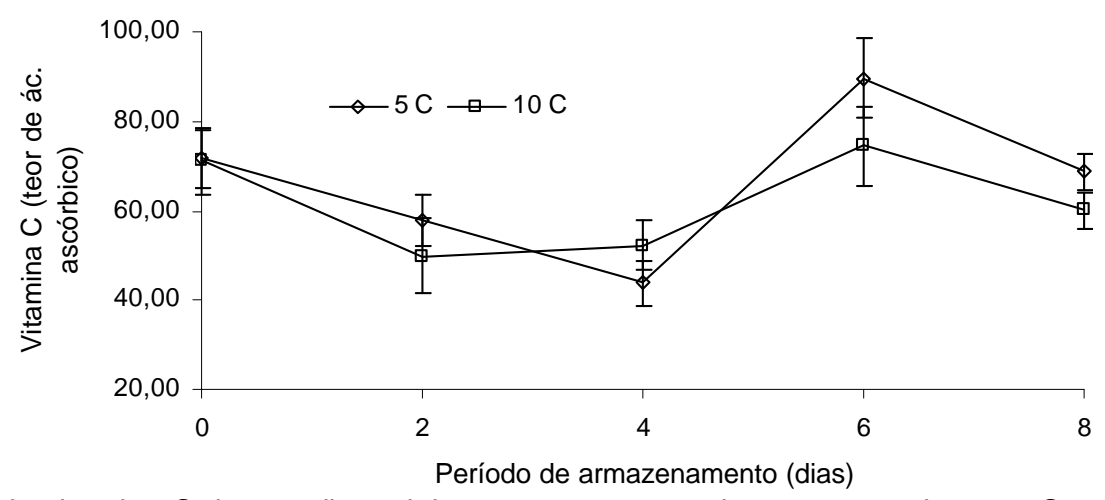

FIGURA 4 - Teor de vitamina $\mathrm{C}$ de mamões minimamente processados armazenados a $5{ }^{\circ} \mathrm{C}$ e a $10{ }^{\circ} \mathrm{C}$ durante o período de 8 dias. Barras verticais representam o desvio padrão da média $(n=3)$.

\section{CONCLUSÃO}

Pelos resultados obtidos pode-se inferir que, embora não tenha sido observada diferenças físicoquímicas significativas nos mamões armazenados a $5^{\circ} \mathrm{C}$ e $10^{\circ} \mathrm{C}$, a temperatura de $10^{\circ} \mathrm{C}$ não pode ser utilizada, considerando os elevados riscos de contaminação. Na temperatura de $5^{\circ} \mathrm{C}$, o produto pode ser armazenado durante 8 dias, sem risco de contaminação e sem alterações significativas nas características físico-químicas. 


\section{REFERÊNCIAS}

1. ANÔNIMO. Praticidade impulsiona venda de préprocessados. FrutiFatos, v. 2, n. 2, p. 43-44, 2002

2. ANVISA. Agência Nacional de Vigilância Sanitária. Resolução RCD n 12, de 2 de janeiro de 2001. Disponível em <http:// www.anvisa.gov.br>

3. AOAC. Association of Official Analytical Chemists. Official methods of analysis of the Association of Official Analytical Chemistry. 11. ed. Washington: AOAC, 1992. 1115 p.

4. BURNS, J.L. Lightly processed fruits and vegetables: Introduction to the Colloquium. HortScience, v. 30, n. 1, p. 14-17, 1995.

5. CANTWELL, M.I. Fresh-cut products. Perishables Handling Newsletter, v. 81, p. 2-3, 1995.

6. CANTWELL, M.I.; SUSLOW, T.V. Postharvest Handling Systems: Fresh-Cut Fruits and Vegetables. In: KADER, A.A. (Ed.). Postharvest technology of horticultural crops. 3.ed. Davis: University of California, 2002. p. 445-463.

7. CHITARRA, M.I.F. Processamento mínimo de frutos e hortaliças. Viçosa: Centro de Produções Técnicas, 1998.88 p.

8. FAO Statistical Databases. Disponível em <http://www.cnpmf.embrapa.br/planilhas/mmffc99.xls>. Acessado em 05/04/2000.

9. HONG, J. H.; GROSS, K. C. Surface sterilization of whole tomato fruit with sodium hypochlorite influences subsequent postharvest behavior of fresh-cut slices. Postharvest Biology and Technology, v. 13, n. 1, p. 51-58, 1998.

10. GARDNER, P.T.; WHITE, T.A.C.; MCPHAIL, D.B.; DUTHIE, G.G. The relative contribution of vitamin C, carotenoids and phenolics to the antioxidant potential of fruit juices. Food Chemistry, v. 68, p. 471-474, 2000.

11. Klein, B.P. Nutritional consequences of minimal processing of fruits and vegetables. Journal of Food Quality, v.10, p. 179-93, 1987.

12. KLUGE, R.A.; NACHTIGAL, J.C.; FACHINELLO, J.C.; BILHALVA, A.B. Fisiologia e manejo pós-colheita de frutas de clima temperado. 2. ed. Pelotas: UFPEL, 2002. $216 \mathrm{p}$.

13. LEE, D.S.; HAGGAR, P.E.; LEE, J.; YAM, K.L. Model for fresh produce respiration in modified atmospheres based on principle of enzyme kinetics. Journal of Food Science, v. 56, n. 6, p. 1580-1585, 1991.

14. MEDINA, J.C. Cultura. Mamão: cultura, matéria-prima, processamento e aspectos econômicos. Campinas: ITAL, 1995. p. 1177. (Frutas tropicais, 7 )

15. MOHD-SOM, F.; KERBEL, E.; MARTIN, S.E.; SCHMIDT, S.J. Microflora changes in modified atmosphere packaging broccoli florets stores at refrigerated temperature. Journal of Food Quality, v. 17, p. 347-360, 1994.

16. MORETTI, C.L.; MAROUELLI, W.A.; SILVA, W.L.C. Respiratory activity and browning of minimally processed sweet potatoes. Horticultura Brasileira, v. 20, p. 497-500, 2002.

17. O'CONNOR-SHAW, R.E.; ROBERTS, R.; FORD, A.L. ;NOTTINGHAM, S.M. Shelf life of minimally processed honeydew, kiwifruit, papaya, pineapple and cantaloupe. Journal of Food Science, v. 59, p. 1202-1206, 1994.

18. OLIVEIRA JR, L.F.G. Conservação pós-colheita de mamão (Carica Papaya L.) utilizando atmosfera modificada em diferentes temperaturas de armazenamento. Campos dos Goytacazes, 2002. 82 f. Dissertação (Mestrado) - Universidade Estadual do Norte Fluminense Darcy Ribeiro.

19. OLIVEIRA JR, L.F.G.; COELHO, E.M.; COELHO, F.C. Armazenamento de mamão 'golden', em condições de atmosfera modificada. Revista Brasileira de Armazenamento, v. 29, n. 2, p. 139-142, 2004.

20. PEREIRA, L.M.; RODRIGUES, A.C.P.; SARANTOPOULOS, C.I.G.L.; JUNQUEIRA, V.C.A.; CORDEIRO, H.M.A.B.; HUBINGER, M.D. Vida-de-prateleira de goiabas minimamente processadas acondicionadas em embalagem sob atmosfera modificada. Ciência e Tecnologia de Alimentos, v. 23, n. 3, p. 427-433, 2003.

21. SOUZA, R.A.M. Mercado para produtos minimamente processados. Informações Econômicas, v. 31, n. 3, p. 7-18, 2001.

22. TEIXEIRA, G. H. A.; DURIGAN, J. F.; MATTIUZ, BEN-HUR; ROSSI Jr, O. D. Processamento mínimo de mamão 'Formosa' Ciência e Tecnologia de Alimentos, v. 21, n. 1, p. 47-50, 2001.

23. THOMAS, P. Radiation preservation of foods of plant origin. III-Tropical fruits: bananas, mangoes and papayas. Critical Reviews in Food Science and Nutrition, v. 23, n. 2, p. 147-205, 1986.

24. VANDERZANT, C; SPLITTSTOESSER, D.F. Compendium of methods the microbiological examination of foods. Washington: American Public Health Association, 1992.

25. VITTI, M.C.D.; KLUGE, R.A.; GALLO, C.R.; SCHIAVINATO, M.A.; MORETTI, C.L.; JACOMINO, A.P. Aspectos fisiológicos e microbiológicos de beterrabas minimamente processadas. Pesquisa . Agropecuária Brasileira., v. 39, n. 10, p. 1027-1032, 2004.

26. ZAGORY, D.; KADER, A.A. Modified atmosphere packaging of fresh produce. Food Technology, v. 42, n. 9, p. 70-77, 1988.

Recebido em 24/07/2006 Aceito em 30/05/2007 